\title{
Are homografts superior to conventional prosthetic valves in the setting of infective endocarditis involving the aortic valve?
}

\author{
Joon Bum Kim, MD, PhD,, a, Julius I. Ejiofor, MD, ${ }^{\mathrm{c}}$ Maroun Yammine, $\mathrm{MD},{ }^{\mathrm{c}}$ Janice M. Camuso, RN, \\ Conor W. Walsh, BA, ${ }^{\mathrm{d}}$ Masahiko Ando, MD, PhD, ${ }^{\mathrm{a}}$ Serguei I. Melnitchouk, MD, ${ }^{\mathrm{a}}$ James D. Rawn, MD, \\ Marzia Leacche, MD, ${ }^{c}$ Thomas E. MacGillivray, MD, ${ }^{a}$ Lawrence H. Cohn, MD, ${ }^{\mathrm{c}}$ John G. Byrne, MD, ${ }^{\mathrm{c}}$ and \\ Thoralf M. Sundt, MD
}

\begin{abstract}
Background: Surgical dogma suggests that homografts should be used preferentially, compared with conventional xenograft or mechanical prostheses, in the setting of infective endocarditis (IE), because they have greater resistance to infection. However, comparative data that support this notion are limited.

Methods: From the prospective databases of 2 tertiary academic centers, we identified 304 consecutive adult patients (age $\geq 17$ years) who underwent surgery for active IE involving the aortic valve (AV), in the period 2002 to 2014. Shortand long-term outcomes were evaluated using propensity scores and inverseprobability weighting to adjust for selection bias.
\end{abstract}

Results: Homografts, and xenograft and mechanical prostheses, were used in 86 $(28.3 \%), 139(45.7 \%)$, and $79(26.0 \%)$ patients, respectively. Homografts were more often used in the setting of prosthetic valve endocarditis $(58.1 \%$ vs $28.8 \%, P=.002)$ and methicillin-resistant Staphylococcus $(25.6 \%$ vs $12.1 \%$, $P=.002)$, compared with conventional prostheses. Early mortality occurred in $17(19.8 \%)$ in the homograft group, and $20(9.2 \%)$ in the conventional group $(P=.019)$. During follow-up (median: 29.4 months; interquartile-range: 4.772.6 months), 60 (19.7\%) patients died, and $23(7.7 \%)$ experienced reinfection, with no significant differences in survival $(P=.23)$ or freedom from reinfection rates $(P=.65)$ according to the types of prostheses implanted. After adjustments for baseline characteristics, using propensity-score analyses, use of a homograft did not significantly affect early death (odds ratio $1.61 ; 95 \%$ confidence interval [CI], 0.73-3.40, $P=.23$ ), overall death (hazard ratio $1.10 ; 95 \% \mathrm{CI}, 0.62-1.94$, $P=.75$ ), or reinfection (hazard ratio $1.04 ; 95 \% \mathrm{CI}, 0.49-2.18, P=.93$ ).

Conclusions: No significant benefit to use of homografts was demonstrable with regard to resistance to reinfection in the setting of IE. The choice among prosthetic options should be based on technical and patient-specific factors. Lack of availability of homografts should not impede appropriate surgical intervention. (J Thorac Cardiovasc Surg 2016;151:1239-48)

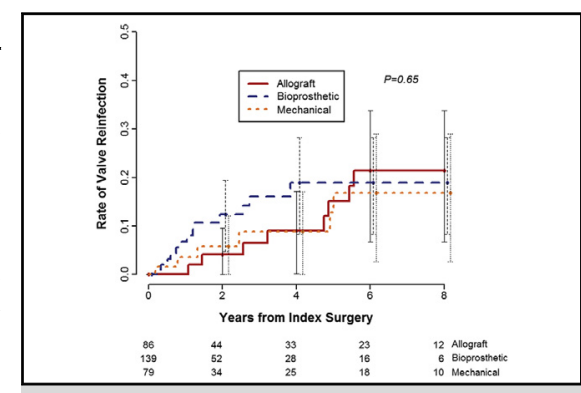

Kaplan-Meier plots for freedom from reinfection according to type of implanted valve.

\section{Central Message}

Use of homografts showed no significant benefit compared with conventional prosthetic valves, in the setting of infective endocarditis.

\section{Perspective}

Among 304 adult patients with active endocarditis undergoing AV replacement, the use of homografts did not demonstrate significant benefit, compared with conventional prosthetic valves, in survival or freedom from reinfection. Therefore, patient-specific factors, such as patient preferences and technical elements, should be the principal drivers of choices for valve prostheses.

See Article page 1251.

See Editorial Commentary page 1249.

See Editorial page 1230 .

\footnotetext{
From the ${ }^{\text {a Division }}$ of Cardiac Surgery, Massachusetts General Hospital, Harvard Medical School; ' ${ }^{\mathrm{D}}$ Department of Thoracic and Cardiovascular Surgery, Asan Medical Center, University of Ulsan College of Medicine, Seoul, South Korea; 'Division of Cardiac Surgery, Brigham and Women's Hospital, Harvard Medical School; and ${ }^{\mathrm{d}}$ Tufts University School of Medicine, Boston, Mass.

The American Association for Thoracic Surgery (AATS) provided funding for this research to Joon Bum Kim, who is the 63rd AATS Graham Foundation Travelling Fellow.

Read at the 41st Annual Meeting of The Western Thoracic Surgical Association, Whistler, British Columbia, Canada, June 24-27, 2015.

Received for publication June 19, 2015; revisions received Nov 25, 2015; accepted for publication Dec 13, 2015; available ahead of print Feb 28, 2016.

Address for reprints: Thoralf M. Sundt, MD, Massachusetts General Hospital, Cox 652, 55 Fruit St, Boston, MA 02114 (E-mail: tsundt@partners.org). $0022-5223 / \$ 36.00$

Copyright (c) 2016 by The American Association for Thoracic Surgery http://dx.doi.org/10.1016/j.jtcvs.2015.12.061
}

Recurrence of infection after valve replacement for infective endocarditis (IE) is a strong concern, and accordingly, the optimal prosthesis in this setting has been debated for decades. ${ }^{1-4}$ Surgical dogma suggests that autologous or allogeneic tissue is preferable to synthetic material in an infected field. Given reluctance to use foreign artificial

Scanning this QR code will take you to the supplemental figure and tables for this article.

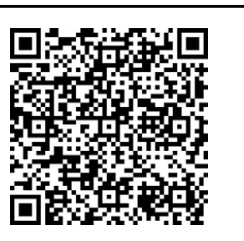




\section{Abbreviations and Acronyms \\ $\mathrm{AV}=$ aortic valve \\ $\mathrm{CI}=$ confidence interval \\ $\mathrm{HR}=$ hazard ratio \\ IE = infective endocarditis \\ $\mathrm{PVE}=$ prosthetic valve endocarditis}

materials, as with conventional mechanical or stented xenograft valve prostheses, homografts have been advocated by some, with favorable outcomes reported, particularly in cases involving prosthetic valve endocarditis (PVE) and other complex and aggressive lesions, such as root abscess formation..$^{5-8}$ Most of these reports, however, are single-armed observational studies without conventional prostheses that can be used as comparators. $^{5-8}$

Obstacles to the use of homografts remain, however: Implantation is technically more complex and is not universally taught. Use of homografts in the current era is as a complete aortic root replacement in almost all cases, and the aggressive nature of this procedure may be the major drawback in recommending it to patients already at high risk of operative mortality. ${ }^{1,9}$ In addition, durability of homografts is limited, which may be a limiting factor, particularly among young patients. ${ }^{10,11}$ Finally, such grafts are relatively scarce and require cryopreservation. Therefore, the notion that homografts are required may in practice present an obstacle to appropriate surgical management of patients who have IE.

Despite strong opinion, limited data are available, comparing operative outcomes for homograft versus conventional prosthetic valves in the setting of IE. Given that we have access to data from 2 institutions with similar referral patterns from the same patient pool, and diverse views on the preferred prosthesis, we felt that we had a unique dataset for analysis. We therefore reviewed our combined experience to compare short- and long-term outcomes for homograft versus conventional prosthetic replacements in patients who have active IE involving the AV requiring surgical therapy.

\section{METHODS}

\section{Study Subjects and Outcome Measures}

Using separate cardiac surgery databases from Massachusetts General Hospital and Brigham and Women's Hospital, we identified 304 adult patients (age $\geq 17$ years) who underwent $\mathrm{AV}$ replacement for active IE, in the period January 2002 to August 2014 ( $n=141$ and $n=163$, for the 2 institutions, respectively). The patients were categorized based on the type of implanted AV: homograft (homograft group); mechanical prostheses (mechanical group); or xenograft prostheses (xenograft group).

Primary outcomes of interest were death and valve-related complications, including reinfection or reoperation of the heart valves, thromboembolic events, and anticoagulation-related bleeding. The definitions of valve-related complications, as well as the "active form" of IE, were based on the guidelines of the Society of Thoracic Surgeons. ${ }^{12}$ Early mortality was defined as death occurring either in-hospital or within 30 days of surgery.

Follow-up clinical data were obtained from a centralized clinical data warehouse of Partners Healthcare that encompasses all patient encounters within the system. ${ }^{13}$ For further verification regarding mortality, the Social Security Death Index was searched if necessary. The study protocol was approved by the Institutional Review Board of Partners Healthcare, which encompasses Massachusetts General Hospital and Brigham and Women's Hospital. The requirement for informed consent from individual patients was waived because of the retrospective nature of the study design.

\section{Statistical Analysis}

Categorical variables, presented as frequencies and percentages, were compared using $\chi^{2}$ analysis or the Fisher exact test. Continuous variables, expressed as mean \pm standard deviation, or median with range (or interquartile range), were compared using the Student unpaired $t$ test (between 2 groups) or a 1-way analysis of variance (among 3 groups), as appropriate. Kaplan-Meier analyses were used to assess the probability of survival or freedom from valve-related complications, and log-rank tests were used to compare intergroup differences.

To adjust for differences in baseline characteristics between the homograft and conventional prostheses groups, propensity-score analyses were used as a weighting variable to create 2 well-balanced cohorts, using the weighting methodology of inverse probability of treatment. ${ }^{14-16}$ Propensity scores were generated using multiple logistic regression analysis. Variables used included all preoperative variables listed in Tables 1 and 2, as well as aorta replacement and coronary artery bypass grafting (both categorical). Concomitant root replacement was not included as one of the covariates in the model, because homograft replacement is not independent of root replacement. Discrimination and calibration of propensity scores were assessed with $\mathrm{C}$ statistics and Hosmer-Lemeshow statistics, respectively. Scores for patients receiving homograft replacement were weighted using the term 1/propensity score; those for patients receiving conventional prostheses were weighted using the term $1 /(1-$ propensity score). Weighted logistic regression and weighted Cox proportional hazard analyses were performed. We assumed that the impact of types of implanted valves on the risks of reinfection would differ between the homograft and conventional prosthetic groups, across the early and late postoperative periods. To address this issue, landmark analyses were performed, split into 2 intervals: $\leq 360$ days; and $>360$ days after surgery. ${ }^{17}$

Multivariable Cox proportional hazards models, using a stepwise, backward-elimination technique that included variables with a $P$ value $\leq .20$ in univariable analyses, were run to elicit independent risk factors for our outcomes of interest. Only variables with a $P$ value $<.10$ were included in the final model. For the PVE subgroup analyses, new propensity scores for homograft versus conventional prostheses were calculated using the same methodology. Weighted logistic regression and weighted Cox proportional hazard analyses were performed. R statistical software, version 3.1.2 (https://www.r-project.org/), was used for statistical analyses. All reported $P$ values were the result of 2-tailed tests.

\section{RESULTS \\ Baseline Characteristics}

Homografts, mechanical prostheses, and xenograft prostheses were used in $86(28.3 \%), 79(26.0 \%)$, and 139 patients $(45.7 \%)$, respectively. The baseline demographic and clinical profiles of patients, according to the type of AV implanted, are summarized in Table 1. Overall, patients in the xenograft group were oldest, followed in descending order by those in the homograft and mechanical prostheses 
TABLE 1. Baseline demographic and clinical variables

\begin{tabular}{|c|c|c|c|c|c|c|}
\hline \multirow[b]{2}{*}{ Variable } & \multirow{2}{*}{$\begin{array}{c}\text { Homograft } \\
(\mathbf{n}=\mathbf{8 6})\end{array}$} & \multirow{2}{*}{$\begin{array}{c}\text { Mechanical } \\
(\mathrm{n}=79)\end{array}$} & \multirow{2}{*}{$\begin{array}{c}\text { Xenograft } \\
(\mathbf{n}=139)\end{array}$} & \multicolumn{3}{|c|}{$P$ value } \\
\hline & & & & Overall & Homograft vs mechanical & Homograft vs xenograft \\
\hline \multicolumn{7}{|l|}{ Demographic } \\
\hline Age (y) & $55.6 \pm 16.6$ & $47.2 \pm 14.5$ & $59.8 \pm 14.6$ & .001 & $<.001$ & .049 \\
\hline Male gender & $63(73.3)$ & $60(75.9)$ & $105(75.5)$ & .91 & .69 & .70 \\
\hline Race & & & & .62 & .98 & .24 \\
\hline White & $75(87.2)$ & $68(86.1)$ & $129(92.8)$ & & & \\
\hline Black & $3(3.5)$ & $3(3.8)$ & $4(2.9)$ & & & \\
\hline Asian & $2(2.3)$ & $2(2.5)$ & $3(2.2)$ & & & \\
\hline Other & $3(3.5)$ & $2(2.5)$ & 0 & & & \\
\hline Unknown & $3(3.5)$ & $4(5.1)$ & $3(2.2)$ & & & \\
\hline IV drug user & $15(17.4)$ & $16(20.3)$ & $16(11.5)$ & .19 & .64 & .21 \\
\hline \multicolumn{7}{|l|}{ Patient's medical history } \\
\hline \multicolumn{7}{|l|}{ Diabetes mellitus } \\
\hline No insulin therapy & $9(10.5)$ & $4(5.1)$ & $17(12.2)$ & .23 & .20 & .69 \\
\hline Insulin therapy & $5(5.8)$ & $2(2.5)$ & $13(9.4)$ & .14 & .30 & .34 \\
\hline \multicolumn{7}{|l|}{ Smoking } \\
\hline Past & $28(32.6)$ & $24(30.4)$ & $46(33.1)$ & .92 & .76 & .93 \\
\hline Current & $15(17.4)$ & $10(12.7)$ & $16(11.5)$ & .43 & .39 & .21 \\
\hline NYHA functional class III or IV & $47(54.7)$ & $27(34.2)$ & $74(53.2)$ & .011 & .008 & .84 \\
\hline$\underline{\text { Serum creatinine level }(\mathrm{mg} / \mathrm{dL})}$ & $1.32 \pm 0.71$ & $1.56 \pm 1.47$ & $1.52 \pm 1.03$ & .15 & .18 & .13 \\
\hline
\end{tabular}

Values are $\mathrm{n}(\%)$, or mean \pm standard deviation, unless otherwise indicated. $I V$, Intravenous; NYHA, New York Heart Association.

groups $(P<.001)$. Patients with advanced heart failure symptoms were more common in the homograft group, compared with the mechanical group $(P=.008)$; however, the prevalence was similar in the homograft and xenograft groups $(P=.84)$.

In terms of IE pathogens, methicillin-resistant staphylococci was the most common in the homograft group $(25.6 \%)$, whereas the viridans group streptococci was the leading cause of IE in the mechanical $(38.0 \%)$ and xenograft groups $(25.2 \%)$ (Table 2$)$. Patients who received homografts had PVE $(P<.001)$ and abscess formation more often $(P<.001)$, compared with those who received conventional prostheses; however, multivalve involvement $(P<.001)$ and severe valve dysfunction $(P=.006)$ were more common in the latter group (Table 2). Conversely, among patients with PVE, $45.0 \%$ had homografts placed.

All patients, except for one, received aortic root replacement in the homograft group $(98.8 \%)$; whereas 30 of $218(13.8 \%)$ patients undergoing conventional prosthetic replacement received a root replacement procedure $(P<.001$; Table 2). Cardiopulmonary bypass and aortic crossclamping times were significantly longer in the homograft group than in the other 2 groups (Table 2).

\section{Unadjusted Outcomes}

Early mortality occurred in 17 of $86(19.8 \%)$ patients in the homograft group, and 20 of 218 patients $(9.2 \%)$ in the conventional prostheses groups $(P=.011)$. Follow-up was challenging in this cohort; follow-up data for valve-related complications were complete for 230 $(75.7 \%)$ patients, with a median duration of 29.4 months (interquartile range: 4.7-72.6 months). During study observation, $60(20.4 \%)$ deaths occurred, along with 47 (15.5\%) valve-related complications (Table 3). KaplanMeier analyses of survival, and freedom from valve-related complications showed no significant differences among the 3 groups. Specifically, freedom from reinfection at 5 years was $84.9 \% \pm 5.8 \%$, $83.2 \% \pm 6.7 \%$, and $81.1 \% \pm 5.1 \%$ in the homograft, mechanical, and xenograft groups, respectively $(P=.65)$ (Figures 1 and 2; Figure E1, Online Data Supplement).

\section{Adjusted Outcomes}

The propensity-score model for the overall cohort showed C statistics of 0.821 , and a Hosmer-Lemeshow goodness-of-fit $P$ value of .647; these indicate reasonable discrimation and calibration profiles of the propensityscore model. After weighting, baseline variables were well balanced among the treatment groups (Table E1, Online Data Supplement). After risk adjustment, no evidence was found that homograft usage significantly affects early or long-term mortality, or development of valve-related complications (Table 4).

Adjusted Kaplan-Meier curves for rate of valve reinfection for the homograft versus conventional prosthetic groups indicate that the use of a homograft did not significantly affect overall risk of reinfection (Figure 3). Landmark analyses revealed that the risk of reinfection within 1 year showed a trend toward being lower (not statistically significant) in the homograft group (hazard ratio [HR]: $0.33 ; 95 \% \mathrm{CI}, 0.05-2.01 ; P=.23$ ), compared with the conventional prosthetic group. After 1 year, the HR was 1.59 (95\% CI, 0.64-3.93), with $P=.31$. 
TABLE 2. Profiles on infective endocarditis and surgical procedure

\begin{tabular}{|c|c|c|c|c|c|c|}
\hline \multirow[b]{2}{*}{ Profile data } & \multirow[b]{2}{*}{$\begin{array}{c}\text { Homograft } \\
(\mathbf{n}=\mathbf{8 6})\end{array}$} & \multirow[b]{2}{*}{$\begin{array}{c}\text { Mechanical } \\
(\mathbf{n}=79)\end{array}$} & \multirow[b]{2}{*}{$\begin{array}{c}\text { Xenograft } \\
(n=139)\end{array}$} & \multicolumn{3}{|c|}{$P$ value } \\
\hline & & & & Overall & $\begin{array}{c}\text { Homograft vs } \\
\text { mechanical }\end{array}$ & $\begin{array}{c}\text { Homograft vs } \\
\text { xenograft }\end{array}$ \\
\hline Embolic events & $26(30.2)$ & $15(19.0)$ & $47(33.8)$ & .065 & .095 & .58 \\
\hline Cerebral & $23(26.7)$ & $10(12.7)$ & $36(25.9)$ & .046 & .024 & .89 \\
\hline Bacteriology & & & & .002 & .005 & .044 \\
\hline Viridans streptococcus & $12(14.0)$ & $30(38.0)$ & $35(25.2)$ & & & \\
\hline Other Streptococcus & $9(10.5)$ & $3(3.8)$ & $16(11.5)$ & & & \\
\hline \multicolumn{7}{|l|}{ Staphylococcus } \\
\hline Methicillin-susceptible & $15(17.4)$ & $7(8.9)$ & $27(19.4)$ & & & \\
\hline Methicillin-resistant & $22(25.6)$ & $10(12.7)$ & $16(11.5)$ & & & \\
\hline Entercococcus & $11(12.8)$ & $11(13.9)$ & $26(18.7)$ & & & \\
\hline Other & $8(9.3)$ & $6(7.6)$ & $12(8.6)$ & & & \\
\hline Negative culture & $9(10.5)$ & $12(15.2)$ & $7(5.0)$ & & & \\
\hline Multiple valves affected & $14(16.3)$ & $33(41.8)$ & $29(20.9)$ & $<.001$ & $<.001$ & .40 \\
\hline Mitral valve affected & $11(12.8)$ & $30(38.0)$ & $26(18.7)$ & $<.001$ & $<.001$ & .24 \\
\hline Tricuspid valve affected & $4(4.7)$ & $4(5.1)$ & $3(2.2)$ & .45 & .90 & .30 \\
\hline Vegetation diameter $>10 \mathrm{~mm}$ & $36(41.9)$ & $43(54.4)$ & $66(47.5)$ & .27 & .11 & .41 \\
\hline Abscess formation & $58(67.4)$ & $32(40.5)$ & $41(29.5)$ & $<.001$ & $<.001$ & $<.001$ \\
\hline Prosthetic endocarditis & $50(58.1)$ & $31(39.2)$ & $30(21.6)$ & $<.001$ & .015 & $<.001$ \\
\hline Biological & $31(36.0)$ & $14(17.7)$ & $23(16.5)$ & $<.001$ & .008 & $<.001$ \\
\hline Mechanical & $19(22.1)$ & $17(21.5)$ & $7(5.0)$ & $<.001$ & .93 & $<.001$ \\
\hline Severe dysfunction of affected valves & $49(57.0)$ & $57(72.2)$ & $107(77.0)$ & $<.001$ & .042 & .002 \\
\hline Left ventricular ejection fraction $(\%)$ & $57.8 \pm 11.9$ & $60.1 \pm 9.5$ & $60.0 \pm 11.6$ & .17 & .16 & .17 \\
\hline Emergency surgery & $86(28.3)$ & $18(22.8)$ & 139 (45.7) & .91 & .68 & .75 \\
\hline Preoperative intra-aortic balloon pump & $5(5.8)$ & $5(6.3)$ & $5(3.6)$ & .61 & .89 & .43 \\
\hline \multicolumn{7}{|l|}{ Associated surgical procedures } \\
\hline Aortic root replacement & $85(98.8)$ & $15(19.0)$ & $15(10.8)$ & $<.001$ & $<.001$ & $<.001$ \\
\hline Aorta replacement & $16(18.6)$ & $11(13.9)$ & $27(19.4)$ & .58 & .41 & .88 \\
\hline Coronary bypass & $30(34.9)$ & $16(20.3)$ & $14(10.1)$ & .022 & .036 & $<.001$ \\
\hline Cardiopulmonary bypass time (min) & $318.2 \pm 146.5$ & $235.0 \pm 129.4$ & $181.4 \pm 136.6$ & $<.001$ & $<.001$ & $<.001$ \\
\hline Cardiac ischemic time (min) & $236.1 \pm 100.7$ & $177.1 \pm 91.7$ & $136.8 \pm 89.5$ & $<.001$ & $<.001$ & $<.001$ \\
\hline
\end{tabular}

Values are $\mathrm{n}(\%)$, or mean \pm standard deviation, unless otherwise indicated.

When the outcome analyses were further adjusted for root replacement procedure in the weighted regression models, early mortality (odds ratio: $0.65 ; 95 \% \mathrm{CI}$, $0.24-1.80 ; P=.40$ ), overall death (HR $0.67 ; 95 \%$ CI, $0.33-1.35 ; P=.26$ ), and reinfection (HR $0.47 ; 95 \%$ CI, $0.14-1.59 ; P=.22$ ), as well as other valve-related events
( $P$ value range: $.18-.96)$, did not significantly differ in the homograft versus conventional prosthetic groups.

Stepwise multivariable Cox hazard analyses revealed that the following independent risk factors affected overall mortality (composite of early and late mortality): insulin-dependent diabetes mellitus (HR 2.91; 95\% CI,

TABLE 3. Summary of adverse outcomes

\begin{tabular}{|c|c|c|c|c|c|c|}
\hline \multirow[b]{2}{*}{ Variables } & \multirow[b]{2}{*}{$\begin{array}{c}\text { Homograft } \\
(\mathbf{n}=\mathbf{8 6})\end{array}$} & \multirow[b]{2}{*}{$\begin{array}{c}\text { Mechanical } \\
(n=79)\end{array}$} & \multirow[b]{2}{*}{$\begin{array}{c}\text { Xenograft } \\
(\mathbf{n}=139)\end{array}$} & \multicolumn{3}{|c|}{$P$ value* } \\
\hline & & & & Overall & $\begin{array}{c}\text { Homograft vs } \\
\text { mechanical }\end{array}$ & $\begin{array}{c}\text { Homograft vs } \\
\text { xenograft }\end{array}$ \\
\hline Early (30-d or in-hospital) death & $17(19.8)$ & $10(12.7)$ & $10(7.2)$ & .019 & .22 & .005 \\
\hline Overall death & $23(26.7)$ & $15(19.0)$ & $22(15.8)$ & .13 & .24 & .047 \\
\hline Valve-related events & $14(16.3)$ & $11(13.8)$ & $22(15.8)$ & .90 & .67 & .93 \\
\hline Reinfection & $6(7.0)$ & $5(6.3)$ & $12(8.6)$ & .65 & .68 & .63 \\
\hline Valve reoperation & $11(12.8)$ & $4(5.1)$ & $9(6.5)$ & .22 & .090 & .72 \\
\hline Thromboembolism & $1(1.2)$ & $3(3.8)$ & $7(5.0)$ & .15 & .24 & .073 \\
\hline Anticoagulation-related hemorrhage & $1(1.2)$ & $4(5.1)$ & $5(3.6)$ & .30 & .14 & .12 \\
\hline Composite of death and valve-related events & $35(40.7)$ & $23(29.1)$ & $34(24.5)$ & .035 & .12 & .010 \\
\hline
\end{tabular}

Values are $\mathrm{n}(\%)$, unless otherwise indicated. ${ }^{*} \chi^{2}$ analysis for early mortality and log-rank test for overall death, valve-related complications, and composite of death and valve-related complications. 


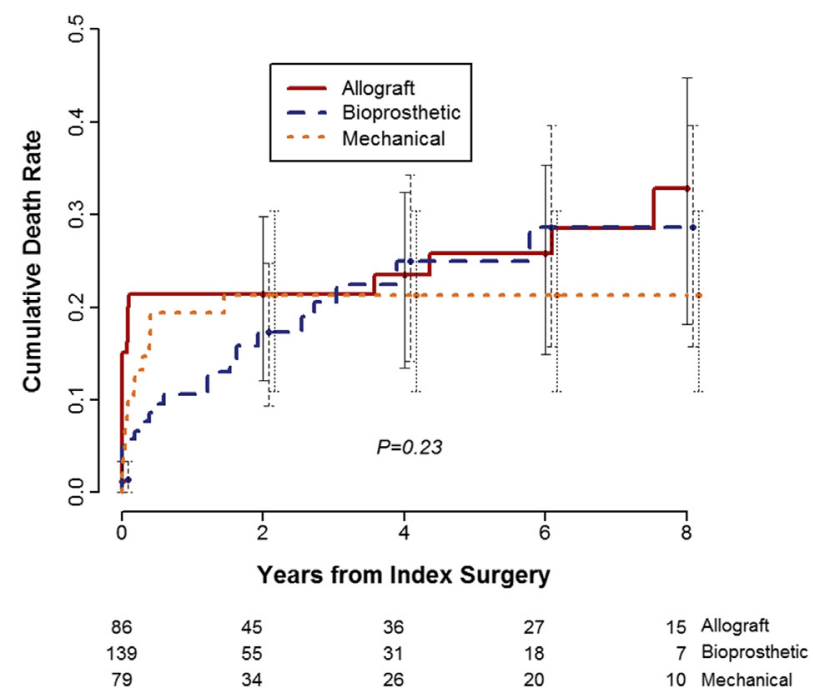

FIGURE 1. Unadjusted Kaplan-Meier plots for overall mortality, according to type of valve implanted. Longitudinal bar plots indicate $95 \%$ confidence intervals $($ solid $=$ allograft; dashed $=$ bioprosthetic; dotted $=$ mechanical).

1.28-6.58; $P=.010$ ); baseline serum-creatinine level (HR 1.20; 95\% CI, 1.02-1.42; $P=.033$ ); methicillin-resistant Staphylococcus infection (HR 2.55; 95\% CI, 1.42-4.25; $P=.001$ ); multivalve IE (HR 2.55; 95\% CI, 1.45-4.50; $P=.001)$; PVE (HR 1.72; 95\% CI, 1.01-2.95; $P=.047$ ); preoperative intra-aortic balloon pump placement (HR 3.68; 95\% CI, 1.64-8.27; $P=.002$ ); and root replacement procedure (HR 2.03; 95\% CI, 1.17-3.52; $P=.012$ ). The use of a homograft was not a significant predictor of mortality in the multivariable model (HR $0.70 ; 95 \% \mathrm{CI}$, $0.32-1.51 ; P=.36)$. Independent risk factors for reinfection

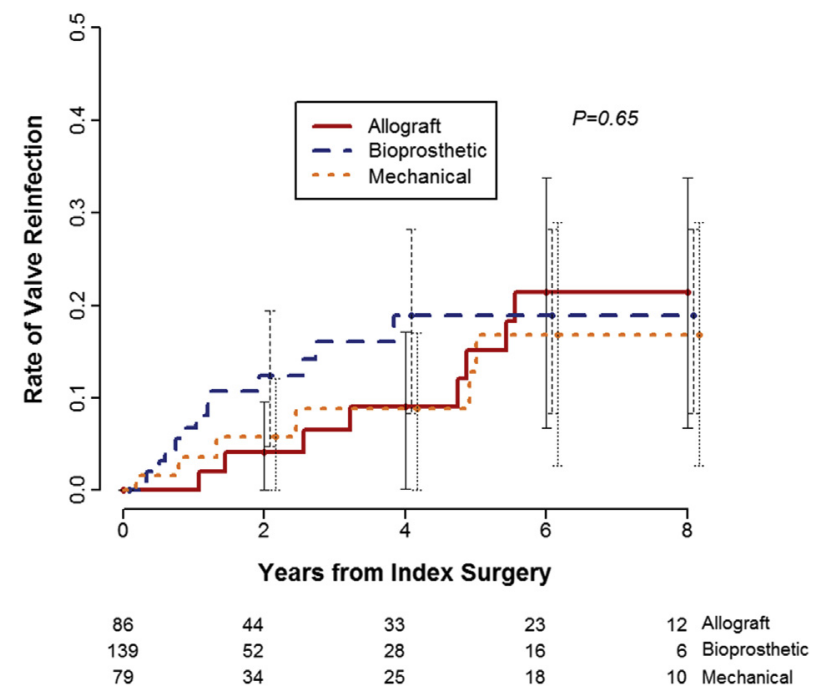

FIGURE 2. Unadjusted Kaplan-Meier plots for cumulative rates of reinfection, according to type of valve implanted. Longitudinal bar plots indicate $95 \%$ confidence intervals $($ solid $=$ allograft; dashed $=$ bioprosthetic; dotted $=$ mechanical $)$. in the final multivariable model were as follows: current intravenous drug user (HR 7.68; 95\% CI, 3.30-17.88; $P<.001$ ); multivalve IE (HR 2.28; 95\% CI, 0.97-5.38; $P=.059)$; and severe dysfunction of the affected valves (HR 7.70; 95\% CI, 1.03-57.39; $P=.046$ ). However, use of a homograft was not a significant predictor of reinfection (HR 0.49; 95\% CI, 0.18-1.35; $P=.167$ ).

\section{Prosthetic Valve Endocarditis: A Subgroup Analysis}

Of the 111 patients with PVE, $50(45.0 \%)$ patients received a homograft replacement, whereas the other 61 $(55.0 \%)$ received either a mechanical $(n=31)$ or xenograft $(\mathrm{n}=30)$ prosthesis. The early mortality rate among those with PVE was similarly elevated, at $22.0 \%$ for homografts and $19.7 \%$ for conventional prostheses $(P=.76)$. Unadjusted analyses showed no significant differences in the incidence of individual or composite adverse outcomes for homografts versus conventional prosthetic valve replacement in patients with PVE (Table 4). After risk adjustment (propensity-score model performance (C statistic $=0.840$; Hosmer-Lemeshow $P=.940$; Table E2, Online Data Supplement), outcomes were not significantly affected by the type of prosthesis implanted (Table 4).

\section{DISCUSSION}

The present study demonstrates no advantage to using one prosthetic option rather than another in the setting of IE; more specifically, the use of homograft prostheses had no apparent advantage in survival or freedom from valverelated complications, including reinfection, compared with conventional mechanical prosthetic or xenograft valves. A higher early mortality rate overall was seen in the homograft group; however, this finding is attributable to the poorer baseline conditions of this group, as riskadjusted analyses yielded similar results among the groups.

Our findings suggest that patient-specific factors, such as age and implant preference, as well as technical reconstructive considerations, should drive prosthetic choice, rather than surgical dogma. Although homograft reconstruction is preferred by many surgeons, including some in our group, their implantation is technically more complex, unfamiliar to many surgeons, and requires access to a homograft bank, and these are not universally available. The implication of our results is that surgical intervention for complex IE should not be withheld based solely on the notion that homografts are required in this setting.

The homograft option is appealing from both a theoretical and practical standpoint. Fundamental surgical principles support use of a tissue rather than a prosthetic option in an infected area, in the interest of minimizing the risk of recurrent infection. The homograft limits prosthetic material to the sutures themselves. By these same principles, aortic allografts have been advocated in the past, as an alternative to extra-anatomic reconstruction 
TABLE 4. Comparive outcomes of homograft replacement versus conventional prosthetic implantation

\begin{tabular}{|c|c|c|c|c|c|c|}
\hline \multirow[b]{2}{*}{ Outcome } & \multicolumn{3}{|c|}{ Crude } & \multicolumn{3}{|c|}{ Adjusted } \\
\hline & HR* & $95 \% \mathrm{CI}$ & $P$ value & HR* & $95 \% \mathrm{CI}$ & $P$ value \\
\hline \multicolumn{7}{|l|}{ Overall cohort $(n=304)$} \\
\hline Early mortality & 2.43 & $1.20-4.93$ & .013 & 1.61 & $0.73-3.40$ & .23 \\
\hline Overall mortality & 1.51 & $0.90-2.53$ & .12 & 1.10 & $0.62-1.94$ & .75 \\
\hline Valve-related events & 0.91 & $0.48-1.70$ & .76 & 0.80 & $0.43-1.48$ & .47 \\
\hline Reinfection & 0.97 & $0.44-2.14$ & .93 & 1.04 & $0.49-2.18$ & .93 \\
\hline Valve reoperation & 1.74 & $0.78-3.92$ & .18 & 1.57 & $0.70-3.52$ & .28 \\
\hline Thromboembolism & 0.20 & $0.03-1.55$ & .12 & 0.20 & $0.03-1.22$ & .082 \\
\hline Anticoagulation-related bleeding & 0.23 & $0.03-1.83$ & .16 & 0.12 & $0.01-1.78$ & .13 \\
\hline Death + valve-related events & 1.43 & $0.95-2.16$ & .089 & 1.07 & $0.69-1.66$ & .75 \\
\hline \multicolumn{7}{|c|}{ Prosthetic endocarditis subgroup $(\mathrm{n}=111)$} \\
\hline Early mortality & 1.15 & $0.45-2.90$ & .76 & 1.88 & $0.69-5.24$ & .22 \\
\hline Overall mortality & 1.04 & $0.51-2.11$ & .91 & 1.23 & $0.58-2.60$ & .58 \\
\hline Valve-related events & 0.70 & $0.21-2.41$ & .58 & 0.70 & $0.22-2.26$ & .55 \\
\hline Reinfection & 0.36 & $0.03-3.50$ & .38 & 0.76 & $0.11-5.53$ & .79 \\
\hline Valve reoperation & 0.82 & $0.14-4.95$ & .83 & 0.60 & $0.10-3.71$ & .59 \\
\hline Thromboembolism & NA & NA & NA & NA & NA & NA \\
\hline Anticoagulation-related bleeding & 0.51 & $0.04-5.60$ & .58 & 0.41 & $0.04-4.30$ & .45 \\
\hline Death + valve-related events & 1.03 & $0.55-1.91$ & .94 & 1.19 & $0.62-2.26$ & .60 \\
\hline
\end{tabular}

*For all outcomes except early mortality, which is given as odds ratio. $H R$, Hazard ratio; $C I$, confidence interval; $N A$, not applicable.

for repair of infected descending thoracic or abdominal polyester grafts. ${ }^{18}$ In recent years, however, satisfactory outcomes have been reported for use of polyester grafts in situ in this setting, perhaps in part thanks to improvements in antibiotic therapy. ${ }^{19}$ Similarly, enthusiasm is building for antibiotic therapy alone for some cases of $\mathrm{PVE},{ }^{20}$ a condition previously considered to be a clear indication for surgical intervention. ${ }^{21}$ Accordingly, the theoretical advantage of eliminating prosthetic material in an infected field may be less compelling in the current era.

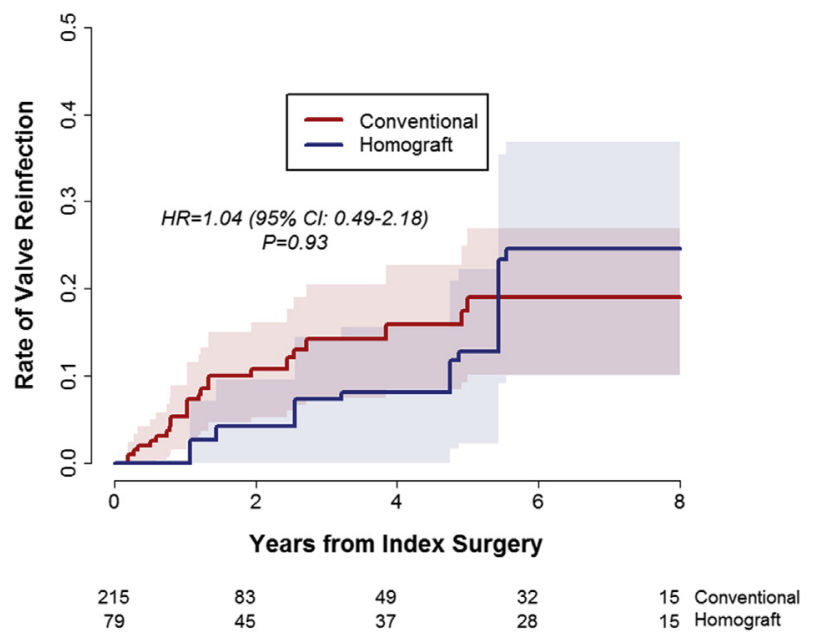

FIGURE 3. Adjusted Kaplan-Meier plots for cumulative rates of reinfection of homograft versus conventional prosthetic (biological or mechanical) replacements. Blue and red shading indicates areas within $95 \%$ confidence intervals, in the homograft and conventional prosthetic groups, respectively (purple shading indicates overlap). HR, Hazard ratio; $C I$, confidence interval.
From a practical technical standpoint, for those experienced in handling homograft material, it affords flexibility in accommodating difficult root anatomy after aggressive debridement of infected tissue. ${ }^{7,22}$ In the setting of active IE, a core principle is complete debridement of septic tissue, which may leave significant tissue defects, prior to reconstruction. With a conventional prosthesis, a patch can be used, created by either pericardial tissue or polyester-woven grafts. ${ }^{23}$ For a homograft, however, the conduit is pliable, and the anterior leaflet of the donor's mitral valve can be employed to accommodate abscess cavities or other tissue defects, either in an orthotopic position or by rotation of the homograft, as needed. Furthermore, the entire homograft inflow can be sutured directly to the muscle of the recipient left ventricular outflow tract in cases of partial or complete aortoventricular disruption, which sometimes occurs, particularly in prosthetic endocarditis. For those surgeons who are unfamiliar with homografts, however, the pliability of the conduit may in fact pose technical challenges and therefore present a disadvantage.

Our findings are consistent with those of Jassar and colleagues, ${ }^{1}$ who evaluated 134 patients undergoing root replacement surgery for IE involving $\mathrm{AV}$, and found that 90 had PVE. In their study, mechanical, nonhomograft biological and homograft prostheses were used in 43, 55, and 36 patients, respectively. They reported no significant differences in the incidences of in-hospital mortality or major complications. During a mean follow-up period of 32.1 months, the 3 patient groups showed comparable valve-related outcomes, including reinfection rates. Several other recent comparative studies on the use of homografts in 
IE, although varied in lesion location, sample size, and use of control groups, have similarly reported that homograft replacement was not superior to mechanical or xenograft prostheses in the treatment of IE. ${ }^{4,22,24-26}$

The current study adds to the literature via its rigorous risk-adjustment methodology to overcome selection bias in our treatment cohort, as well as the relatively heterogeneous attitudes and preferences among the large group of surgeons involved. In general, this group had a tendency to use homografts in more-aggressive forms of IE, such as PVE $(P<.001)$, methicillin-resistant Staphylococcus infection $(P=.002)$, and the presence of root abscess $(P<.001)$. When viewed conversely, however, 26 of $48(54.2 \%)$ patients with this type of infection, 73 of $131(55.7 \%)$ with root abscess, and 61 of $111(55.0 \%)$ with PVE did receive conventional prosthetic replacement. In addition, multivalvular involvement and severe $\mathrm{AV}$ dysfunction were significantly more common among the conventional prosthetic group than the homograft group. This mixed overlap of high-risk patients between the homograft and conventional prosthetic groups provided what we believe are comparable cohorts, allowing us to use statistical methods for risk adjustment to evaluate postoperative outcomes. Our risk-adjusted groups were adequately balanced for measured sources of bias (Tables E1 and E2). These analyses revealed similar short- and long-term outcomes, regardless of which conduit was selected for AV replacement (Table 4).

Prosthetic IE is particularly challenging given the reported high surgical mortality of $10 \%$ to $20 \% .^{1,2,9}$ In addition to the risks inherent in reoperation, the technical aspects of the procedure are complicated by debridement of the infected AV prostheses, including the sewing ring and surrounding infected tissue. In this setting, isolated AV replacement may be challenging, despite motivation to simplify the operation by avoiding root replacement. In our series, however, only 65 of 111 patients $(58.6 \%)$ with PVE underwent root replacement: 49 of $50(98.0 \%)$ in the homograft group, and only 16 of $61(26.2 \%)$ in the conventional prosthetic group $(P<.001)$. Even with this conservative approach in the conventional prosthetic replacement group, long-term outcomes were comparable in both crude and adjusted analyses (Table 4).

These findings may suggest that PVE in the AV does not always necessitate root replacement, but that more conservative $\mathrm{AV}$ replacement may be possible if complete removal of infected tissue leaves adequate root geometry. The less-extensive isolated $\mathrm{AV}$ replacement was correlated with shorter aortic clamping and cardiopulmonary bypass times $(P<.001)$, which may be correlated with lower perioperative risks in this high-risk cohort. This finding additionally implies that patients who are cared for in settings without access to homografts can still undergo surgery for their disease and should not be denied surgery owing to the notion that homografts are necessary in all cases.

\section{Limitations}

This study has limitations inherent to the retrospective observational design. As in any surgical series, one can anticipate surgical bias in the selection of conduits for valve replacement. Although we used appropriate statistical adjustment techniques, residual confounding caused by unmeasured covariates still may have affected our results. Our database includes cases from 2 different institutions, with diverse staff and practice, which helps ameliorate some of the difficulties with single-center designs. Nevertheless, the 2 hospitals share a geographic location, which may affect the generalizability of our findings to other populations.

Although this series is one of the largest that has sought to evaluate the impact of homograft uses on surgical outcomes in the setting of IE, the study might have been underpowered for testing the study hypotheses, owing to an insufficient sample size. The study results, therefore, should be interpreted with caution and need to be validated by further, larger-scale studies.

Obtaining reliable follow-up data regarding valve-related complications was challenging given the significant attrition of patients $(>20 \%)$. The institutional review board did not approve direct contact with patients as a means to obtain follow-up information, owing to the involvement of sensitive (intravenous drug use) information, by which longitudinal data were restricted to use within Partners Healthcare-affiliated hospitals in Massachusetts. This lack of complete follow-up data may have affected the overall validity of the study results.

\section{CONCLUSIONS}

No significant benefits of homograft, compared with standard, prosthetic valves were demonstrated with regard to reinfection or survival, in the setting of IE affecting AV. These findings suggest that patient-specific factors, such as patient preferences and technical considerations, should be the principal drivers of choices of valve prostheses. Furthermore, lack of access to homografts should not be considered an obstacle to surgical therapy for this serious condition.

\section{Conflict of Interest Statement}

Thoralf M. Sundt, MD, is a consultant for Thorasos Therapeutics. All other authors have nothing to disclose with regard to commercial support.

\section{References}

1. Jassar AS, Bavaria JE, Szeto WY, Moeller PJ, Maniaci J, Milewski RK, et al. Graft selection for aortic root replacement in complex active endocarditis: Does it matter? Ann Thorac Surg. 2012;93:480-7. 
2. Perrotta S, Lentini S. In patients with severe active aortic valve endocarditis, is a stentless valve as good as the homograft? Interact Cardiovasc Thorac Surg. 2010;11:309-13.

3. Sweeney MS, Reul GJ Jr, Cooley DA, Ott DA, Duncan JM, Frazier OH, et al. Comparison of bioprosthetic and mechanical valve replacement for active endocarditis. J Thorac Cardiovasc Surg. 1985;90:676-80.

4. Klieverik LM, Yacoub MH, Edwards S, Bekkers JA, Roos-Hesselink JW, Kappetein AP, et al. Surgical treatment of active native aortic valve endocarditis with allografts and mechanical prostheses. Ann Thorac Surg. 2009;88:1814-21.

5. Perrotta S, Aljassim O, Jeppsson A, Bech-Hanssen O, Svensson G. Survival and quality of life after aortic root replacement with homografts in acute endocarditis. Ann Thorac Surg. 2010;90:1862-7.

6. Preventza O, Mohamed AS, Cooley DA, Rodriguez V, Bakaeen FG, Cornwell LD, et al. Homograft use in reoperative aortic root and proximal aortic surgery for endocarditis: a 12-year experience in high-risk patients. $J$ Thorac Cardiovasc Surg. 2014:148:989-94.

7. Lund O, Chandrasekaran V, Grocott-Mason R, Elwidaa H, Mazhar R, Khaghani A, et al. Primary aortic valve replacement with allografts over twenty-five years: valve-related and procedure-related determinants of outcome. J Thorac Cardiovasc Surg. 1999;117:77-90; discussion 91.

8. Yankah AC, Klose H, Petzina R, Musci M, Siniawski H, Hetzer R. Surgical management of acute aortic root endocarditis with viable homograft: 13-year experience. Eur J Cardiothorac Surg. 2002;21:260-7.

9. Musci M, Weng Y, Hubler M, Amiri A, Pasic M, Kosky S, et al. Homograft aortic root replacement in native or prosthetic active infective endocarditis: twentyyear single-center experience. J Thorac Cardiovasc Surg. 2010;139:665-73.

10. Fukushima S, Tesar PJ, Pearse B, Jalali H, Sparks L, Fraser JF, et al. Long-term clinical outcomes after aortic valve replacement using cryopreserved aortic allograft. J Thorac Cardiovasc Surg. 2014;148:65-72.e2.

11. Shah DK, Li Z, Park SJ, Daly RC, Dearani JA, Schaff HV, et al. Replacement of the infected composite aortic root prosthesis. Ann Thorac Surg. 2011;92:1651-5.

12. Akins CW, Miller DC, Turina MI, Kouchoukos NT, Blackstone EH, Grunkemeier GL, et al. Guidelines for reporting mortality and morbidity after cardiac valve interventions. J Thorac Cardiovasc Surg. 2008;135:732-8.

13. Murphy SN, Chueh HC. A security architecture for query tools used to access large biomedical databases. Proc AMIA Symp. 2002;552-6.

14. Cole SR, Hernan MA. Adjusted survival curves with inverse probability weights. Comput Meth Progr Biomed. 2004;75:45-9.

15. Normand SL. Evaluating the optimal timing of angiography: landmark or off the mark? Circulation. 2007;116:2656-7.

16. Robins JM, Hernan MA, Brumback B. Marginal structural models and causal inference in epidemiology. Epidemiology. 2000;11:550-60.

17. Therneau TM, Grambsch PM. Modeling survival data: extending the Cox model. New York: Springer; 2000.

18. Kieffer E, Bahnini A, Koskas F, Ruotolo C, Le Blevec D, Plissonnier D. In situ allograft replacement of infected infrarenal aortic prosthetic grafts: results in forty-three patients. J Vasc Surg. 1993;17:349-55; discussion 55-6.

19. Fatima J, Duncan AA, de Grandis E, Oderich GS, Kalra M, Gloviczki P, et al. Treatment strategies and outcomes in patients with infected aortic endografts. J Vasc Surg. 2013;58:371-9.

20. Lalani T, Chu VH, Park LP, Cecchi E, Corey GR, Durante-Mangoni E, et al In-hospital and 1-year mortality in patients undergoing early surgery for prosthetic valve endocarditis. JAMA Intern Med. 2013;173:1495-504.

21. Nishimura RA, Carabello BA, Faxon DP, Freed MD, Lytle BW, O'Gara PT, et al. ACC/AHA 2008 Guideline update on valvular heart disease: focused update on infective endocarditis: a report of the American College of Cardiology/American Heart Association Task Force on Practice Guidelines endorsed by the Society of Cardiovascular Anesthesiologists, Society for Cardiovascular Angiography and Interventions, and Society of Thoracic Surgeons. J Am Coll Cardiol. 2008;52: 676-85.

22. David TE, Regesta T, Gavra G, Armstrong S, Maganti MD. Surgical treatment of paravalvular abscess: long-term results. Eur J Cardiothorac Surg. 2007;31:43-8.

23. De Oliveira NC, David TE, Armstrong S, Ivanov J. Aortic and mitral valve replacement with reconstruction of the intervalvular fibrous body: an analysis of clinical outcomes. J Thorac Cardiovasc Surg. 2005;129:286-90.

24. Avierinos JF, Thuny F, Chalvignac V, Giorgi R, Tafanelli L, Casalta JP, et al. Surgical treatment of active aortic endocarditis: Homografts are not the cornerstone of outcome. Ann Thorac Surg. 2007;84:1935-42.

25. Hagl C, Galla JD, Lansman SL, Fink D, Bodian CA, Spielvogel D, et al. Replacing the ascending aorta and aortic valve for acute prosthetic valve endocarditis: Is using prosthetic material contraindicated? Ann Thorac Surg 2002; 74:S1781-5; discussion S92-9.

26. Moon MR, Miller DC, Moore KA, Oyer PE, Mitchell RS, Robbins RC, et al. Treatment of endocarditis with valve replacement: the question of tissue versus mechanical prosthesis. Ann Thorac Surg. 2001;71:1164-71.

Key Words: Infective endocarditis, surgery, valve replacement, homograft, prognosis

\section{Discussion}

Dr Joseph B. Shrager. I wanted to ask if there were any differences in the types of cases or valves between the 2 hospitals, and if so, if that would bias your results.

Dr Joon Bum Kim (Boston, Mass). There were more than 15 to 20 surgeons involved in each hospital, and I did not see any significant differences in long-term valve outcomes or survival outcomes between the 2 hospitals, or among the surgeons.

Dr Shrager. It is great to see the hospitals working together.

Dr Tara Karamlou. I congratulate the authors on their excellent presentation. Dr Kim and colleagues have investigated an important and timely question: whether homografts used in adults with $\mathrm{AV}$ endocarditis lead to improved short- and mid-term outcomes, including mortality, valve-related complications, and reinfection. The authors have used a reasonable number of patients from 2 neighboring institutions, accrued during a 12-year period. The authors segregated patients for some of their analyses, into 3 groups: those receiving homografts; those receiving xenograft valves; and those receiving mechanical valves. They employed, for the most part, appropriate statistical techniques to analyze their retrospective data. Their findings indicate that utilization of homografts offers no advantage for any of the outcomes studied.

I have several questions for the authors. First, this study is essentially a negative study, showing no difference between any of the valve substitutes. This result has been published previously by several authors, who are referenced in the article. Although the patient number is larger than those previously reported, the question remains as to whether this current study, similar to those already published, has adequate power to detect differences. Although it is not as well accepted as prospective power analyses, retrospective power analysis can and ought to be performed in cases such as this, in which the null hypothesis has been accepted. Retrospective power analysis can easily be employed by using observed effect size and the variance and the results of such a study; ie, a retrospective power analysis study would clearly strengthen the authors' contention that homografts do not offer discernable advantages. Have the authors considered such an approach? 
Dr Kim. Thank you, Dr Karamlou. I think the power analysis is a beautiful tool to use to suggest sample sizes for future prospective randomized trials, based on the results of observational studies. In this kind of study, comparing the homograft with other, conventional prosthetic groups, I think reinfection of the operative valves should be considered the most important outcome. In this study, the adjusted ratio for reinfection was 1.04, which means the risk was $4 \%$ higher in the homograft group, compared with the conventional prosthetic group. I do not think this result really shows some reasonable number that could be expected to be shown by the power calculation, because the clinical trial hypothesis should be something like "homografts may be superior to conventional prostheses," or at least "are not inferior to conventional prostheses," but our result shows a small opposite trend, favoring the conventional prosthetic group. Differentiating the $4 \%$ difference, and determining whether it is meaningful, will require a large number of patients. For example, assuming an alpha error of 5\%, as usual, and power of analysis of $80 \%$, as well as an average of $80 \%$ success in prevention of reinfection, we would need $>3000$ patients for a randomized trial. If we want to increase the power, eg, to $90 \%$, the number required is closer to 4000 . Given the rarity of patients who require surgery for endocarditis, this number is not practical for a clinical trial, so we have quite a strong answer for this question. A review of other prior studies on the same issue shows that results regarding the reinfection rates are quite similar to our study results. So I do not think we can achieve a reasonable number for clinical trials to obtain a desired power.

Dr Karamlou. I might urge you to reconsider that thought, on review of your article, but we will leave that for now. The median follow-up time for a study that spans 12 years is exceedingly short, only 29 months; moreover, more than $20 \%$ of the patients were lost to follow-up. The Social Security Death Index can provide some assurance that mortality estimates in the study are accurate, but the same cannot be said for the other outcomes in the study. I was also bothered by the lack of granularity of some of the outcomes. For example, reinfection is an important endpoint, because if the patient had later infection with the same organism, the cause might be that the initial operation failed to adequately debride or remove all infected tissue, or that the valve substitute chosen was less resistant to infection. Can the authors comment on what avenues were followed to ascertain an appropriate follow-up period, and what additional information they can provide regarding reinfection specifically?

Dr Kim. We are completely aware that the incompleteness of follow-up data is a major limitation of this study, and we used the Partners Healthcare database to collect the data on valvular outcomes. This database covers all patients encountered in Partners Healthcare centers, including all Harvard Medical School-affiliated hospitals, as well as several more secondary and tertiary hospitals in the Massachusetts area. We regarded patients as lost to follow-up if they were not being monitored in these centers in January 2015, and those patients were treated as censored at the time of latest visit in terms of valvular outcome monitoring. Regarding reinfection, there were about 28 patients who had reinfection during follow-up, including 9 patients in the homograft group, and of these 28 patients, none had early-onset (defined as 30 days postoperatively), reinfection, according to the current guidelines. Eight patients had intermediate-onset (defined as between 30 days and 1 year postoperatively) reinfection, and the remaining 20 patients had late-onset reinfection, after 1 year postoperatively. These figures suggest that the initial surgery did quite well in debriding infective tissue, and I do not find any significant differences in the patterns between the homograft and conventional process groups in recurrence of infection.

Regarding cause of pathogens, approximately $20 \%$ of patients were found to have the same organism at recurrence as they did at the index surgery, and another $25 \%$ of patients had culture-negative results, possibly attributable to the prompt microbiotherapy initiation. The remaining $50 \%$ of patients were affected by a different organism, compared with the initial in-depth surgery; again, I did not find any significant difference among the 3 groups of patients.

Dr Karamlou. Okay, clearly, that is important information to include in the article.

I have a final question. I applaud the authors for their efforts at reducing selection bias through the use of propensity scores; statistical methods to limit bias are not infallible, of course, and I am suspicious that, despite their adjustment, some of the variables that were identified in the propensity models are actually surrogates for the type of valve substitute. For example, the authors found that both multivalve endocarditis and severe dysfunction of the affected valves were risk factors for reinfection. However, both of these variables were significantly more prevalent among the nonhomograft groups. Do the authors feel as if they can, based on their analysis, definitively state that homografts are not protective for reinfection? Thank you for the opportunity to discuss this article.

Dr Kim. Thank you for your important question. There are always risks of confounding effects in an observational study, even with rigorous statistical adjustments. Measurable bias, however, can be effectively controlled by some statistical models such as propensity analysis, as we used in our study. To minimize the risks of 
potential residual confounding, we tried to include as many variables as possible for baseline variables. There were 30 such variables, which included multivalve infection, as well as the severe valve dysfunction. The balancing tables are attached in the online data supplement (Tables E1 and E2) in our article, and you can find the balancing levels. I do not think we have significant differences between the 2 groups of patients in any measurable variables.

Dr Craig Seltzman (Utah). It looks like you have a mixture of effects, if the leaflets are not involved. Unless you were in Boston in a certain era, you might not do a full homograft, so I am wondering if you just compared the root replacements? Because with a different patient, you have biological roots, mechanical roots, and composite valve grafts-did you look at just the root population to see if there were any differences?

Dr Kim. Great question-there were only a few patients who had full root replacement in the conventional prosthetic group, and many patients could not be matched, using the propensity score, to compare the root replacement results. However, we could adjust for that factor in the additional multivariable model, and we did not find a significant impact of the type of procedure on the outcomes, even though we performed a subgroup analysis for root replacement patients. However, I admit that the number of patients is very small within the population, so I think we need further study for that particular subset of patients.
Dr Craig Baker (Los Angeles, Calif). This is an important topic, and I will be brief. Many of us were trained here, and we had to use homografts for endocarditis. As many of our practices evolved, it was no longer what we typically do, and these data are consistent with a lot of other papers. But, you operate on endocarditis for multiple reasons: You can have wide-open valve failure, and you can have mobile vegetations. A lot of those have been treated successfully with antibiotics, and it would make intuitive sense that if you sterilize the operative field it does not matter if you put in a homograft or a prosthetic valve. I think the subgroup that does not get mentioned is the one with patients who have active clinical infection at the time of operation, with pus in the aortic mitral curtain. Did you look at that subset, because it is different than sterilized patients who have been on an antibiotic for 4 or 5 days? I did not see that the study addressed that, but that is the group for whom I would be concerned that a homograft is necessary-if there is pus in the aortic wall and so forth.

Dr Kim. Great question. We followed the Society of Thoracic Surgeons definitions when we decided whether it was active or inactive. For example, the active form of endocarditis is defined as needing prompt use of antibiotics at the time of surgery, so we were not able to take a detailed look at whether the patients had a fresh abscess or an organized abscess, or whether it was in the treated, healing-process stage, so I cannot clearly answer your specific question. 

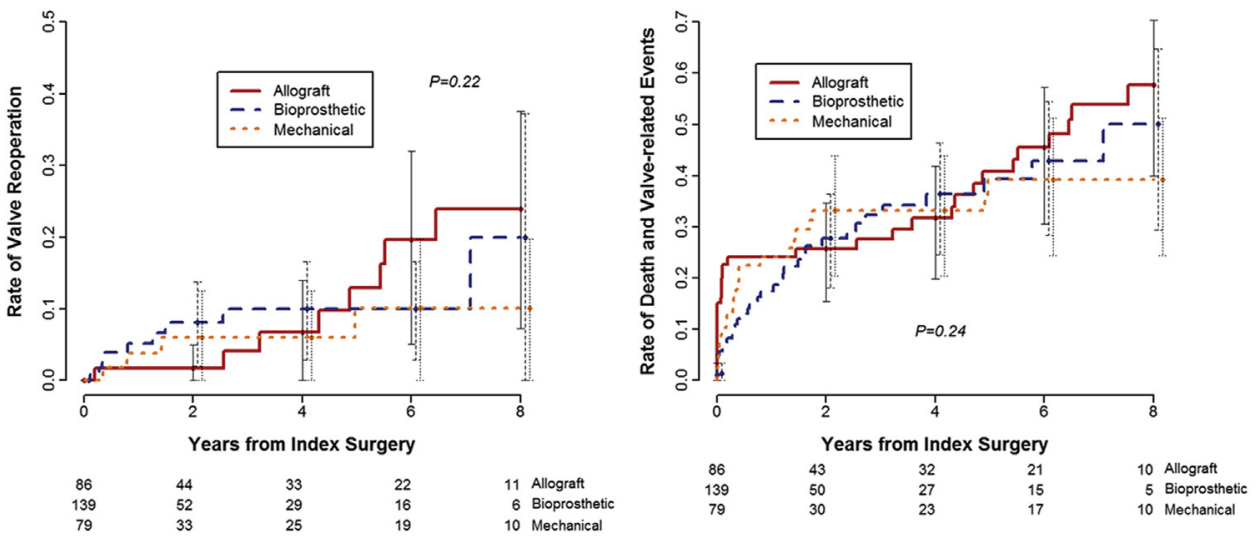

FIGURE E1. Unadjusted Kaplan-Meier plots for cumulative rates of valve reoperation (left), and composite of death and valve-related complications (right), according to types of valve implanted. Longitudinal bar plots indicate $95 \%$ confidence intervals $($ solid $=$ allograft; dashed $=$ bioprosthetic; dotted $=$ mechanical) 
TABLE E1. Baseline balance table for overall cohort, after adjustment using inverse-probability weighting based on propensity scores

\begin{tabular}{|c|c|c|c|}
\hline Characteristics & $\begin{array}{l}\text { Homograft } \\
(\mathbf{n}=\mathbf{8 6})\end{array}$ & $\begin{array}{c}\text { Conventional } \\
\text { prosthesis } \\
(\mathbf{n}=\mathbf{2 1 8}) \\
\end{array}$ & $\begin{array}{c}P \\
\text { valu } \\
\end{array}$ \\
\hline Age (y) & $53.1 \pm 17.0$ & $55.0 \pm 16.2$ & .49 \\
\hline Male gender & 76.5 & 76.7 & .98 \\
\hline \multicolumn{4}{|l|}{ Race } \\
\hline White & 89.9 & 91.6 & \\
\hline Black & 1.3 & 2.8 & \\
\hline Asian & 3.8 & 2.3 & \\
\hline Other & 2.5 & 4.7 & \\
\hline Unknown & 2.5 & 2.8 & \\
\hline IV drug user & 18.2 & 15.8 & .70 \\
\hline \multicolumn{4}{|l|}{ Diabetes mellitus } \\
\hline Without insulin therapy & 7.4 & 8.8 & .68 \\
\hline With insulin therapy & 5.0 & 6.3 & .66 \\
\hline Past smoking & 34.8 & 33.2 & .84 \\
\hline Current smoking & 18.2 & 13.5 & .48 \\
\hline NYHA functional class III or IV & 46.0 & 47.8 & .82 \\
\hline Creatinine $(\mathrm{mg} / \mathrm{dL})$ & $1.39 \pm 0.86$ & $1.48 \pm 1.09$ & .56 \\
\hline Embolic events & 24.3 & 26.8 & .71 \\
\hline Cerebral & 21.2 & 20.7 & .94 \\
\hline $\begin{array}{l}\text { Methicillin-resistant } \\
\text { Staphylococcus infection }\end{array}$ & 16.1 & 15.7 & \\
\hline Multiple valves affected & 19.9 & 24.3 & .52 \\
\hline Mitral valve affected & 17.7 & 21.7 & .55 \\
\hline Tricuspid valve affected & 2.7 & 3.0 & .85 \\
\hline Vegetation diameter $>10 \mathrm{~mm}$ & 36.5 & 33.7 & .81 \\
\hline Abscess formation & 47.2 & 42.9 & .60 \\
\hline Prosthetic valve endocarditis & 39.5 & 35.7 & .62 \\
\hline Biological & 23.9 & 21.6 & .71 \\
\hline Mechanical & 15.6 & 14.1 & .78 \\
\hline $\begin{array}{l}\text { Severe dysfunction of } \\
\text { affected valves }\end{array}$ & 70.2 & 71.0 & .91 \\
\hline $\begin{array}{l}\text { Left ventricular ejection } \\
\text { fraction }(\%)\end{array}$ & $59.8 \pm 10.9$ & $59.5 \pm 10.9$ & .86 \\
\hline Emergency surgery & 23.9 & 23.7 & .98 \\
\hline Preoperative IABP & 3.9 & 4.6 & .80 \\
\hline Aorta replacement & 15.6 & 17.1 & .77 \\
\hline CABG & 20.7 & 19.3 & .81 \\
\hline
\end{tabular}

Values are $\%$, or mean \pm standard deviation, unless otherwise indicated. $I V$, Intravenous; $N Y H A$, New York Heart Association; IABP, intra-aortic balloon pump; $C A B G$, coronary artery bypass graft.
TABLE E2. Baseline balance table in patients with prosthetic valve endocarditis, after adjustment using inverse-probability weighting based on propensity scores

\begin{tabular}{|c|c|c|c|}
\hline Characteristic & $\begin{array}{c}\text { Homograft } \\
(\mathbf{n}=\mathbf{5 0})\end{array}$ & $\begin{array}{c}\text { Conventional } \\
\text { prostheses } \\
(\mathbf{n}=61)\end{array}$ & $\begin{array}{c}P \\
\text { value }\end{array}$ \\
\hline Age $(y)$ & $60.1 \pm 13.1$ & $60.5 \pm 15.7$ & .90 \\
\hline Male gender & 86.7 & 85.2 & .81 \\
\hline Race & & & .41 \\
\hline White & 93.4 & 88.0 & \\
\hline Black & 3.3 & 4.0 & \\
\hline Asian & 1.6 & 0 & \\
\hline Other & 0 & 4.0 & \\
\hline Unknown & 1.6 & 4.0 & \\
\hline IV drug user & 9.4 & 9.8 & .95 \\
\hline \multicolumn{4}{|l|}{ Diabetes mellitus } \\
\hline Without insulin therapy & 11.9 & 11.0 & .89 \\
\hline With insulin therapy & 7.4 & 6.8 & .92 \\
\hline Past smoking & 36.8 & 37.9 & .93 \\
\hline Current smoking & 7.4 & 6.8 & .92 \\
\hline NYHA functional class III or IV & 40.4 & 43.9 & .76 \\
\hline Creatinine $(\mathrm{mg} / \mathrm{dL})$ & $1.36 \pm 0.77$ & $1.41 \pm 0.62$ & .68 \\
\hline Embolic events & 18.6 & 16.4 & .76 \\
\hline Cerebral & 15.1 & 11.5 & .58 \\
\hline $\begin{array}{l}\text { Methicillin-resistant } \\
\text { Staphylococcus infection }\end{array}$ & 26.4 & 27.0 & .96 \\
\hline Multiple valves affected & 14.4 & 15.7 & .87 \\
\hline Mitral valve affected & 11.9 & 14.2 & .76 \\
\hline Tricuspid valve affected & 2.5 & 1.5 & .67 \\
\hline Vegetation diameter $>10 \mathrm{~mm}$ & 36.5 & 33.7 & .81 \\
\hline Abscess formation & 10.8 & 65.9 & .68 \\
\hline Prosthetic valve endocarditis & 100 & 100 & NA \\
\hline Biological & 54.7 & 57.6 & .81 \\
\hline Mechanical & 45.3 & 42.4 & .81 \\
\hline $\begin{array}{l}\text { Severe dysfunction of } \\
\text { affected valves }\end{array}$ & 44.9 & 44.6 & .98 \\
\hline $\begin{array}{l}\text { Left ventricular ejection } \\
\text { fraction }(\%)\end{array}$ & $56.8 \pm 10.7$ & $57.0 \pm 11.8$ & .95 \\
\hline Emergency surgery & 20.7 & 21.7 & .91 \\
\hline Preoperative IABP & 3.5 & 5.9 & .51 \\
\hline Aorta replacement & 25.5 & 22.5 & .77 \\
\hline CABG & 36.1 & 31.4 & .68 \\
\hline
\end{tabular}

Values are $\%$, or mean \pm standard deviation, unless otherwise indicated. $I V$, Intravenous; NYHA, New York Heart Association; NA, not applicable; IABP, intra-aortic balloon pump; $C A B G$, coronary artery bypass graft. 